\title{
THE PROCESS OF PRODUCING THE STANDARD INSCRIPTION OF ASHURNASIRPAL II AT NIMRUD/KALHU ${ }^{1}$
}

\author{
J. Caleb Howard \\ (caleb.howard@gmail.com)
}

In spite of the fact that the Neo-Assyrian royal inscriptions have been known and read for a century and a half, the mechanics of their production are still poorly understood. Studies thus far have relied mainly on references to production in Neo-Assyrian letters and inferences from the final forms of Neo-Assyrian royal inscriptions. Textual variation between manuscripts of the same composition and the formats and execution of the inscriptions are largely untapped sources of information for the mechanics of production.

The purpose of this dissertation is to reconstruct, in as much detail as the data allow, the process of producing the manuscripts of a single composition among the Neo-Assyrian royal inscriptions, namely, the Standard Inscription of Ashurnasirpal II from Kalhu (modern Nimrud) which was repeated over four hundred times on architectural components of the Northwest Palace, mainly on the faces of stone orthostats. $^{2}$ This reconstruction relies especially on variation among the manuscripts of this composition at all levels of textuality as well as observations on the formatting and execution of the text on the orthostats.

The data-set of the dissertation is presented, organised, and analysed in a series of appendices. Appendix 5 contains a catalogue of all manuscripts of the Standard Inscription known to the author, along with relevant information about the artefacts on which each manuscript was incised, publication information, and textual formatting of the

1 Defended in the Department of Near Eastern Studies of the Johns Hopkins University; supervisor: Paul Delnero.

2 An edition can be found in A. K. Grayson, Assyrian Rulers of the Early First Millennium BC I (1114-859 BC) (RIMA 2; Toronto: University of Toronto Press, 1991), Text A.0.101.23. 
manuscripts. Appendix 4 presents a score (Partitur) of 231 manuscripts of the Standard Inscription, based on first-hand collation of 78 of the manuscripts and collation of the remainder of manuscripts from legible photographs. Each manuscript is cited using a siglum which indicates its primary context in the Northwest Palace and its artefact type, and transliterations of the manuscripts indicate relevant details of textual formatting, such as line breaks and uninscribed space. Appendix 3 tabulates all variants in the Standard Inscription manuscripts in the data-set, categorising them using both rubrics reflecting levels of textuality (variations of palaeography, orthography, grammar, and content) and text-critical rubrics (omissions, additions, and substitutions). Appendix 2 presents all variants in the Standard Inscription manuscripts which are shared by two or more manuscripts at the same places of variation. Appendix 1 presents all variants shared by the manuscripts containing a discrete recension of the Standard Inscription, called the I Recension.

On the basis of these data, a series of eight chapters presents a reconstruction of the process of producing the manuscripts of the Standard Inscription. Chapters 1-3 are introductory, presenting a history of research and project design (Chapter 1), reviewing the primary context of the manuscripts in the Northwest Palace from both texts and archaeology (Chapter 2), and describing the literary context of the Standard Inscription (Chapter 3). Chapters 2 and 3, in particular, show that the Standard Inscription was composed for and installed in the Northwest Palace as a part of a unified building programme, characterised by mutual interaction between text and architecture. Moreover, the compositions represented in the Northwest Palace and other buildings on the citadel at Nimrud contain multiple levels of intertextuality between the compositions, especially in the form of shared blocks of text, called Versatzstücke, which were integrated and shaped in different ways to form the various compositions. This integrated production of multiple, interrelated compositions for the same building project shapes how we view textual variation, even among the manuscripts of the same composition.

Chapter 4 reconstructs the process of producing a master copy of the Standard Inscription. In spite of the fact that no master copy of the Standard Inscription is extant, the existence of such a text is inferred from the hundreds of relatively homogeneous copies of the Standard Inscription. The use of master copies in the production of (multiple 
copies of) Neo-Assyrian royal inscriptions is well attested in NeoAssyrian letters. These letters also attest to the agency of both royal scholars (ummân $\bar{u})$ and Neo-Assyrian kings in the production of these master copies. It is suggested that a master copy was created when one or more royal scholars composed a draft of a Neo-Assyrian royal inscription and, through an unknown number of revisions, and with the king's approval, produced a final polished master copy.

In Chapter 5, it is argued that there was a distinct recension of the Standard Inscription, called the I Recension, since the manuscripts containing it were all from Room I in the Northwest Palace, when their primary contexts can be determined. This recension is characterised by the presence, in a set of twenty manuscripts, of six variants that always and only occur in those manuscripts (Type 1 variants) and of fifteen more variants that occur in the same combination always and only in those manuscripts (Type 2 variants). In the case of Type 2 variants, while these variants may occur in other manuscripts which do not contain the I Recension, they never occur in the same combination. Moreover, none of the more than two hundred other manuscripts of the Standard Inscription contain more than four of these fifteen Type 2 variants. Together, these twenty-one variants make up the variant profile of the I Recension and imply that these manuscripts descend from a common source, the master copy of the I Recension. Tabulation of the variants shared among I Recension manuscripts reveals that distinct sub-groups of I Recension manuscripts contain their own unique Type 1 and Type 2 variants, that is, that these sub-groups share distinct variant profiles. These subsets of shared variant profiles point to the existence of an intermediate stage of transmission between the master copy of the I Recension and the extant manuscripts. These are called intermediate copies, and it is suggested that they were used to expedite the process of transmitting the text of the master copy to numerous orthostats.

Chapter 6 considers the relationship between the I Recension and the recension found in the majority of manuscripts of the Standard Inscription, called the M Recension. It is argued that the M Recension is a compositional development of the I Recension on the basis of the types of variants that exist between the recensions. Three of the Type 1 variants and three of the Type 2 variants that characterise the I Recension are best explained as intentional compositional developments, as ameliorations, toward the text of the M Recension. 
As such, it may be thought that the I Recension preceded the $\mathrm{M}$ Recension. The fact that the I Recension appears to be limited in use to Room I in the Northwest Palace, combined with the likelihood that the I Recension preceded the M Recension, implies that Room I was copied before the other rooms in the palace. After this, the I Recension was apparently pulled from circulation and replaced with the $M$ Recension in the remainder of the palace.

In Chapter 7, the mode of transmission - visual or aural - of the Standard Inscription from the intermediate copies to the extant manuscripts is considered. It is argued that visual copying is more likely than dictation as the chief mode of transmission. The copyists of the manuscripts continually managed the density of their writing vis-àvis the space provided for them on the pre-ruled orthostats, which would seem to have required visual access to exemplars. The types of variants which occur in the manuscripts are better explained on a visual model rather than an aural one. And there are many errors of both addition and omission in the manuscripts which apparently make the text incomprehensible - errors which one would not expect a copyist to make when trying to make sense of something dictated.

Chapter 8 deals with the role of stonemasons in the production of the extant manuscripts of the Standard Inscription. Five types of errors are isolated. These were probably caused by the stonemasons, e.g., omissions of entire signs, leaving conspicuous uninscribed space where those signs should be, or omissions, additions, or substitutions of obligatory wedges in sign complexes. In the latter case, some of the signs were quite common in the cuneiform repertoire, suggesting that the masons did not know how to correctly form even basic cuneiform signs. These phenomena may be explained by positing either that the masons had exemplars provided for them to copy and some signs were difficult to read, or that the masons had temporary patterns traced on to the stone for them to follow; the patterns were occasionally obscured in the course of incising, leading to these errors. 